\title{
Design an Active Method to Calculate the Areas From Remotely Sensed Data by Using Image Processing and Geographical Information System
}

\author{
Rayan Gh. Thanoon
}

\author{
Khansa A. Ahmed \\ Remote Sensing Center \\ Mosul University
}

\author{
Sabah H. Ali \\ Sabah H. Ali
}

(Received 3/6/2008, Accepted 23/11/2008) 
تصميم طريقة فعالة لتقدير المساحات من معطيات التحس النائي باستخدام وسائل المعالجة الرقمية ونظم المعلومات الجغرافية

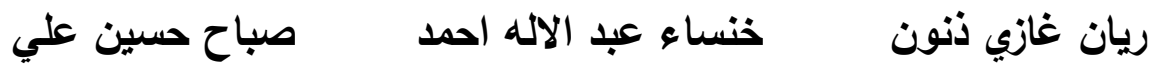 \\ مركز التحسس النائي \\ جامعة الموصل
}

الملخص

تعد مرئيات الأقمار الصناعية من الأدوات المهمة التي نستخدم حاليا في العديد من الدراسات لما

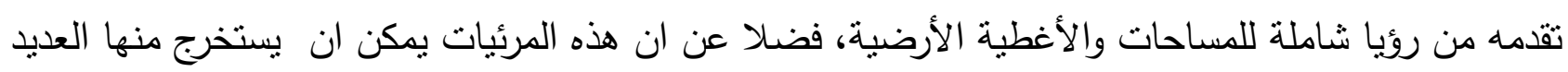

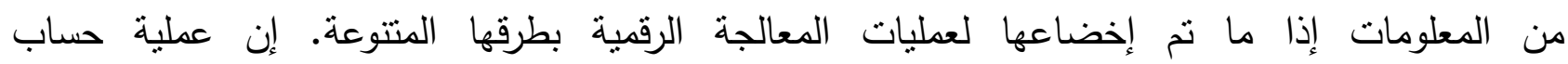
أو تحديد مساحات الأراضي من مرئيات الأقمار الاصطناعية تعد عملية معقدة ليس لكونها تحتاج الى مرئيات

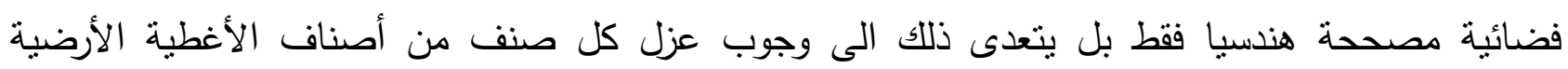
الظاهرة في البيان بشكل واضح لكي بنسنى بعدها تحديد مساحة كل صنف من الأصناف بمستوى مقبول من الدقة.

في الدراسة الحالية تم تصميم طريقة فعالة لاستخلاص وحساب المساحات باستخدام مجموعة من

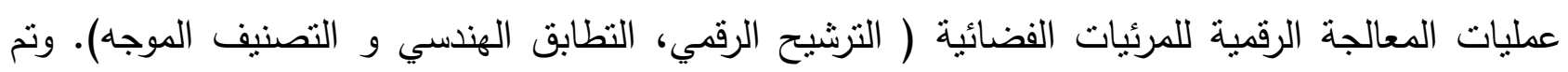

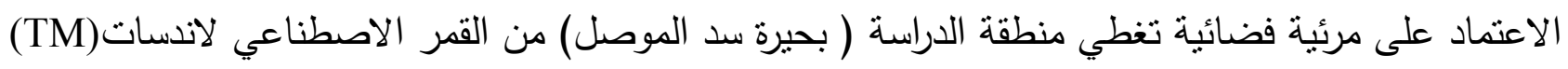

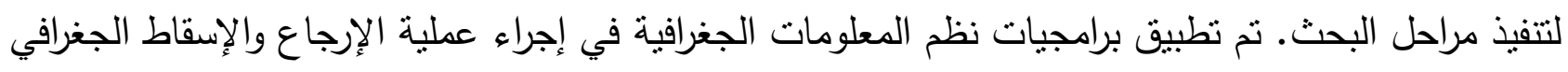

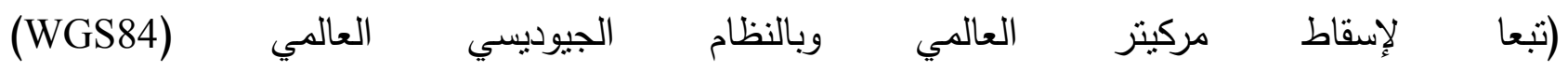

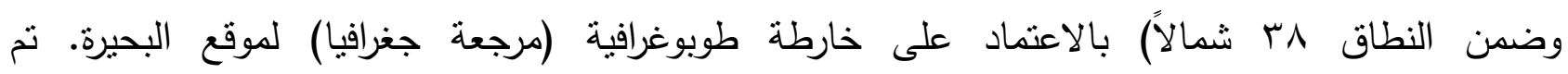
مقارنة نتائج البحث مع النتائج المستحصلة من إحدى برامجيات نظم المعلومات الجغرافية برنامج (Global Mapper 9.2) وقد ثم بعد ذلك مقارنة النتائج أعلاه مع نتائج الطريقة النقليدية في حساب المساحات من الخرائط

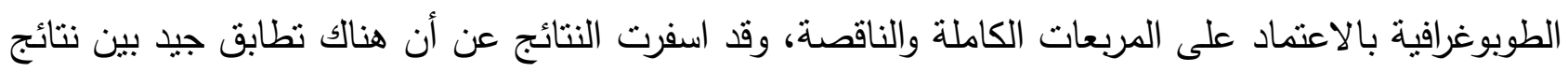

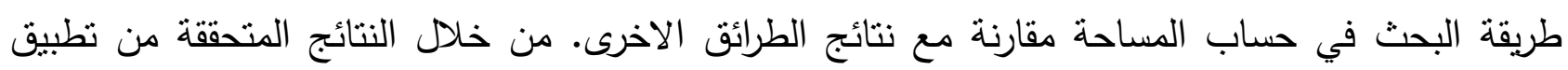

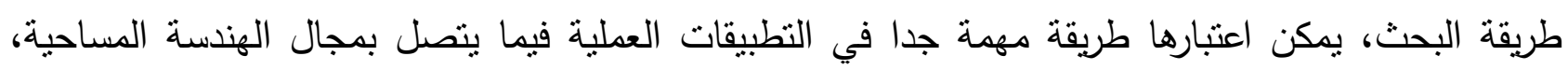
والدراسات البيئية ( التصحر والتلوث البيئي)، الغابات، والتخطيط الحضري، والبئية والجيولوجيا.... الخ. 


\section{INTRODUCTION}

Satellites image became an effective tools or methods for many practical and scientific studies for its comprehensive vision of manifestations of the Earth's surface. It can be used to show locations, distances, size of areas, display geographic relationships, differences, clusters and patterns, in addition to the possibility of extracting a lot of information through the Geographical Information System software and the digital image processing techniques (Zhou, 1999; Kumar, 2008). In geology for example, image could be used in the estimation of sizes and areas of lithological outcrops, ore deposits, water resources, flooding and contamination areas.

The process of determining the area of a particular region in the raw image with a relatively acceptable accuracy is difficult and complex process without the execution of the geometrical and spatial georeferencing processes and identifies a single band and replicated on the image. Generally, the area can be delineated and determine through the GIS software (such as R2V, Global Mapper, and ArcGIS ...etc) and survey tools (such as planometer). These methods perform after the process of digitizing (raster to vector conversion) through either the GIS software or through hand-numbering as in the planometer (Jones, 1997). Based on these methods, the area is calculated with a varying accuracy when applied on the raw satellite image due to lack of a spatial georeferencing and geometrical correction processes as we have previously mentioned. Also, in the previous methods, the process of determination a repetition state of the similar item (class) appearance in overall satellite image required the visual identification of each part of a single class distributed in the image, then the area of the total parts of the single class are collected to be the area of the required class.

The main goal of the current study is to design a method serve as an exemplary workout steps for precisely estimating or calculating the area of any class in the satellite image through a practical application of the digital image processing software. This method can be used to determine all parts of a single desired class directly by accounting of the total number of the pixels in the particular classified region shown in the image.

\section{DATA USED}

Three bands $(3,4,5)$ of Landsat TM row images which were covered the path (170) and row (35) shown in (Fig. 1) have been used in the present study for composing false color image. A topographic map of the Mosul Dam Lake was used for the purpose of geometric correction and georeferencing process. Table (1), lists the specifications of the data used.
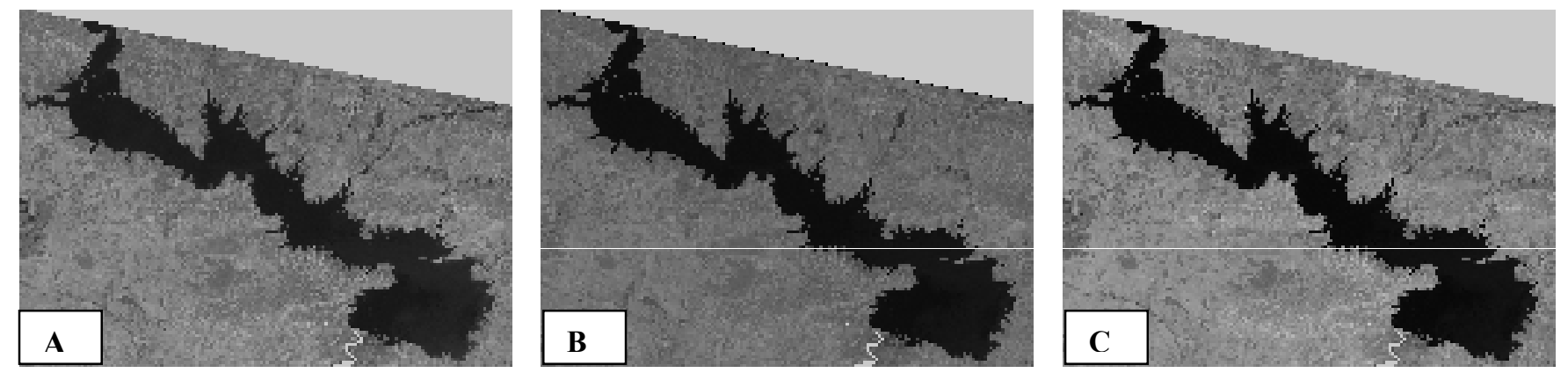

Fig. 1: Landsat (TM) satellite images used
A: Spectral band (3)
B: Spectral band (4)
C: Spectral band (5) 
Table 1: Image and map of the study area

\begin{tabular}{|c|c|c|}
\hline Satellite image & Bands & Date \\
\hline Landsat - Thematic Mapper TM & $3,4,5$ & $28 / 4 / 1987$ \\
\hline Topographic map & Index No. & Date/Scale \\
\hline Dohuk & J-38-S-NE & $1985 / 1: 250.000$ \\
\hline
\end{tabular}

\section{RESEARCH METHODOLOGY}

The flow diagram shown in (Fig. 2) have been designed to calculate any area of any satellite image. It consists of four stages. In order to run the flowchart, Al-Emadi program (Programming by using Visual $\mathrm{C}++$ Language) was adopted in performance all the operations that related to digital filtering, geometrical registration, supervised classification and extraction the number of pixels to each class (Al-Emadi et al., 2004). The main package of this program is shown in (Fig. 3).

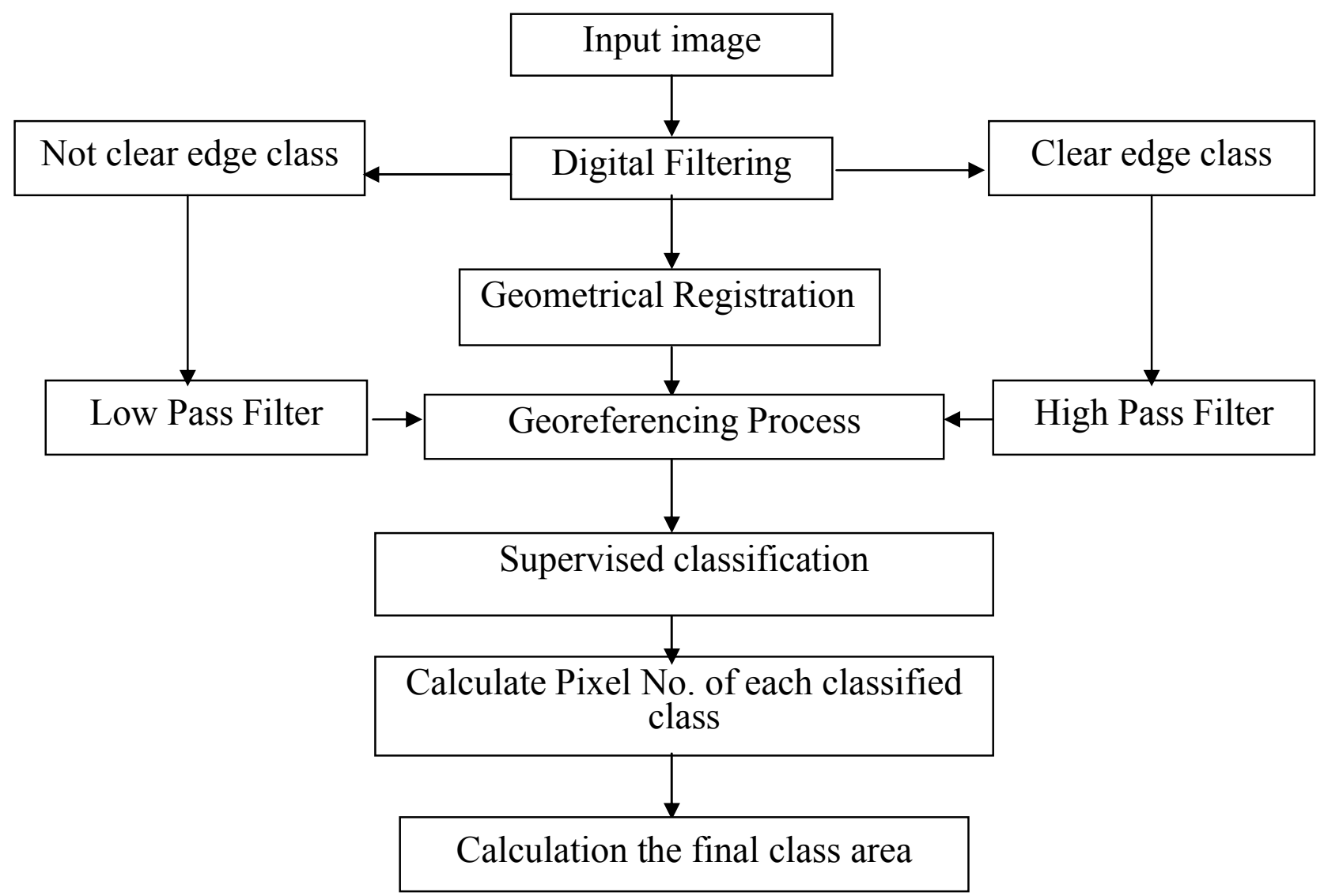

Fig. 2: Flow diagram showing the stages of this study. 


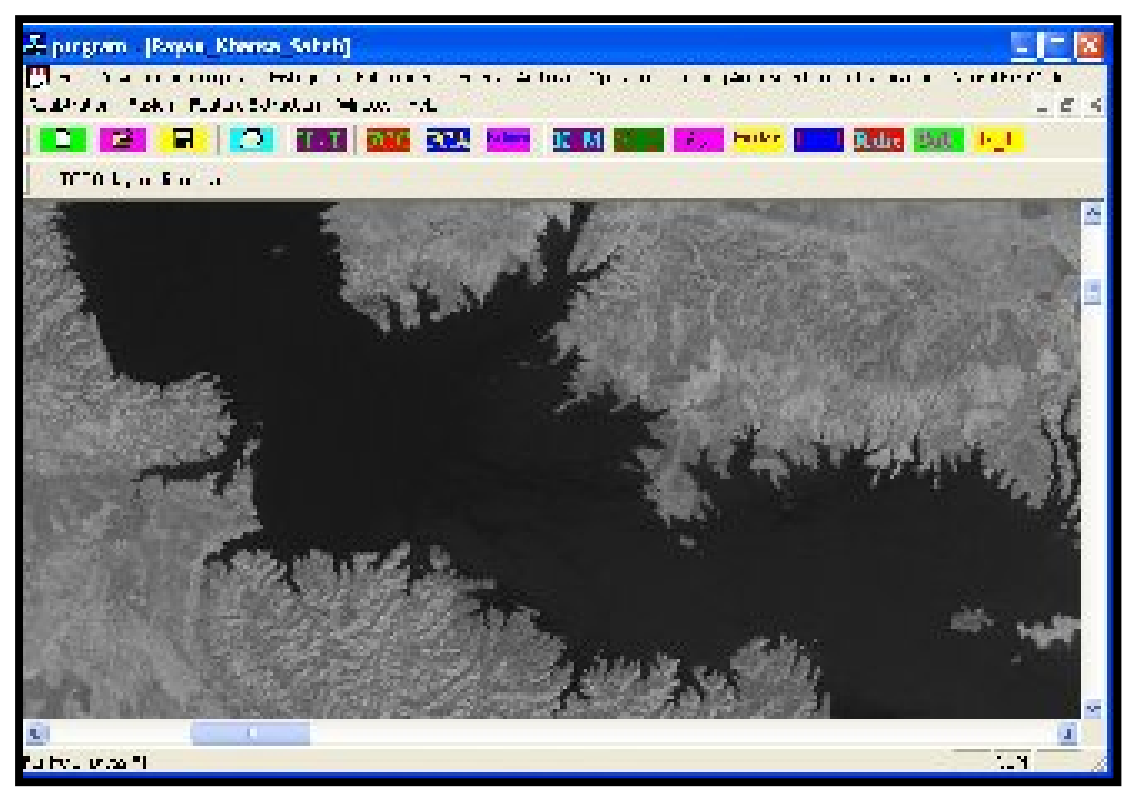

Fig. 3: The main package of Al-Emadi Program (Al-Emadi et al., 2004).

\section{SPATIAL FILTERING}

The main purpose of the digital spatial filtering is either to highlight the classes in the satellite images or obliterating unlike the spectral filtering, which works to stop the spectral energy or passing it in a diverse spectrum (Lillesand and Kiefer, 2000). In the current study and for the purpose of estimating the area of a particular region, the image has been subjected to the spatial filtering as a preprocessing operation for the following reasons.

1. The adopted method used in the current study to calculate the numbers of the pixels for estimating the image area, therefore it must be a clear-cut lines and sharp boundaries between the classes, in other words, the values of the image pixels must be modified. For example, areas of high spatial repetition in the image be rough in the intensity of colors, that means, any gray levels in these regions changed suddenly in a small number of image pixels as shown in the edge of the Dam lake and surrounding areas (Fig. 4). The smooth areas characterized with a low spatial repeating, i. e. the gray levels gradually changed to a relatively large number of image pixels as has been found in agricultural areas adjacent to Lake (Fig. 4). Based on the foregoing, and because the method proposed in the current study is applicable to any satellite image, therefore it must be choose the type of the properly digital filtering depending on the class edges which have been required to calculate its area. High frequency digital filter was applied to highlight the lake from the surrounding area. In the case study required to calculate the area of smooth aspect (characterized by low spatial repeating) therefore it must be used the digitally low pass filter.

2. To facilitate the process of selecting control points on which they depend on the process of geometrical registration, it is preferably that the satellite image subjects to digitally spatial filtering in order to highlight the possible features that can be selected as a ground control points (GCP). In the present study, Laplace digital filtering have been used to complete the spatial filtering process, which consisted of window dimensions $(3 \times 3)$ as explained in the table $(2)$. 
Table r : Filter Mask used to implement the digital Laplacian

\begin{tabular}{|c|c|c|}
\hline 1 & 1 & 1 \\
\hline 1 & -1 & 1 \\
\hline 1 & 1 & 1 \\
\hline
\end{tabular}

This filter taking the difference between pixel and another neighbor's pixel, i.e. each image pixel value must be subtracted from the previous and preceding pixel value, so the values of the mask parameters must be negative to achieve the foregoing, the filtering process is conducted through the following equation (Gonzalez and woods, 2002) :

$$
g(x, y)=\frac{\sum_{s=-a t=-b}^{a} \sum^{b} w(s, t) f(x=s, y+t)}{\sum_{s=-a t=-b}^{a} \sum^{b} w(s, t)} .
$$

Where,

$a=(m-1) / 2, \mathrm{~b}=(\mathrm{n}-1) / 2$.

$\mathrm{w}(\mathrm{s}, \mathrm{t})$ is the mask coefficient

To generate a complete filtered image, Eq. 1 , must be applied for $x=0,1,2, \ldots$

,$M-1$ and $y=0,1,2, \ldots, N-1$

Figuer (4) shown the adopted sub sample scene used in the current study after the applying of digitally spatial filtering. The figure illustrated the boundaries of the lake (high spatial repetition) better than it is visible in the raw, also it shows the improving in the border such as valley.

\section{GEOMETRICAL REGISTRATION}

Usually, satellite image contains geometrical distortions caused by various reasons related to the satellite position, height and speed, as well as secondary causes related to Arcing of the earth and topographical variation (Mather, 1987). The variation in the degree of deformity is depended on the sensor operation and the satellite's orbit.

In the current study, the geometrical registration was applied on the Landsat satellite image covered the study area, which is defined (that is, the process of registration) as a process of geometrical coverage of two or more satellite images, or satellite image with a topographic map for the same region in order to delete the geometrical distortions that existing in one of these images (Jazching, 1989). 

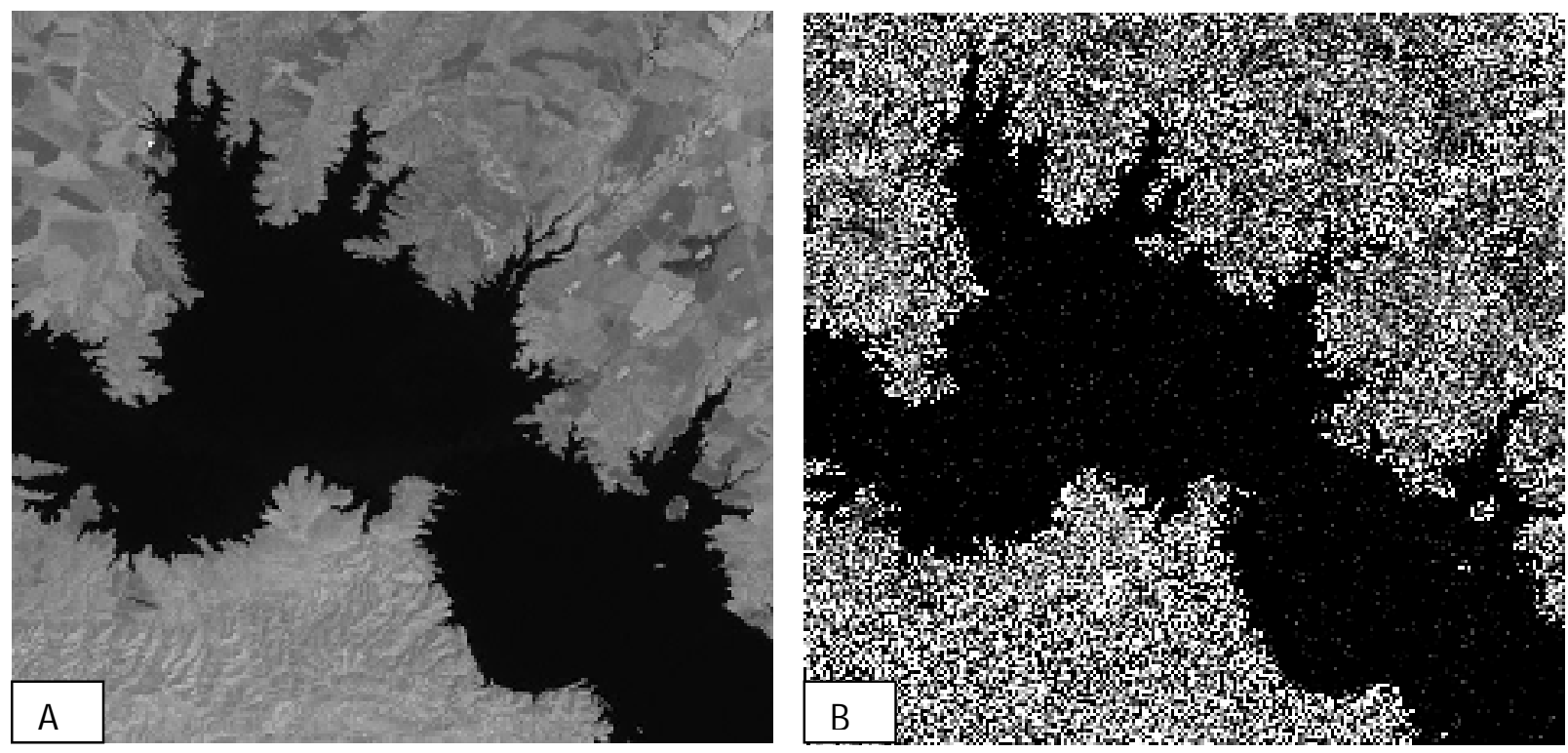

Fig. 4: Digital Filtering Process.

A: Row image before digital filtering process. B: Image after digital filtering process.

There are two main methods for this geometrical registration; manual geometrical registration and automated geometrical registration (Alaaf, 2002). In the first method, the ground control points (GCP) are determined manually by the users, while in the second method the determination of these GCP's are performed by using especial purpose algorithms. In the present study, the manual geometrical registration (image- map) was applied, by which the topographic map of the Mosul Dam Site be the reference map while the Landsat image satellite (of the same region) was the corrected image. In order to obtain relatively high accuracy in the applied geometrical registration, the spatial interpolation (the registration process between the feature of the topographic maps and satellite image) was used. The spatial interpolation required to define a common GCP between map and image, a 25 GCP's were selected to complete the spatial interpolation method, at these numbers of GCP's, the Root Mean Square(RMS) is equal 0.512 which can be acceptable with the resolution of the applied satellite image $(30 \mathrm{~m})$ and the purpose of the present study . The geometrical registration between the topographic map and satellite image was calculated by the following equation (Al-Alaaf, 2002):

$$
\begin{aligned}
& \bar{X}=a_{0}+a_{1} x+a_{2} y \\
& \bar{Y}=b_{0}+b_{1} x+b_{2} y .
\end{aligned}
$$

Where;

$x, y$ is coordinate points of reference image.

$\bar{X}, \bar{Y}$ is coordinate points of corrected image.

$b_{0}, a_{0}$ is the displacement towards $\mathrm{X}, \mathrm{Y}$ respectively.

$b_{1}, a_{1}$ is changing value in the scale towards $\mathrm{X}, \mathrm{Y}$ between the two image.

$b_{2}, a_{2}$ the declination and rotation. 
After execution the above geometrical registration method, the output satellite image will be geometrically corrected (i.e. the image pixel was free from any distortions), therefore the area of any region in the image will be real and identical to the earth surface. The final output image is ready to calculate the area through the present study and other GIS and remote sensing software.

\section{GIS AND GEOREFERENCING PROCESS}

Geographical Information Systems (GIS) can be defined as automated systems for the capture, storage, retrieval, analysis, and display of spatial data (Clarke, 1999). GIS has a better database software allows the management of vast amounts of information that is referenced to digital maps. Global Mapper (GM) is a package software that depending on the GIS dataset.

It is adopted in the present study to perform the georeferencing process of the satellite image for the study area. Georeferencing process is the process of aligning a nongeoreferencing data set to known map coordinates and assigning a coordinate system. Georeferencing creates additional information within the file itself and/or in supplementary files that accompany the image file that tells GIS software how to properly place and draw it (Maling, 1983).

In the present study, the georeferencing process was applied on the non-georeferencing Thematic Mapper (TM) satellite image, the alignment of the coordinates in this image were determined according to several points on the image of known geographical location which representing (in this study) a topographic map which includes the Dam Lake (Fig. 5).

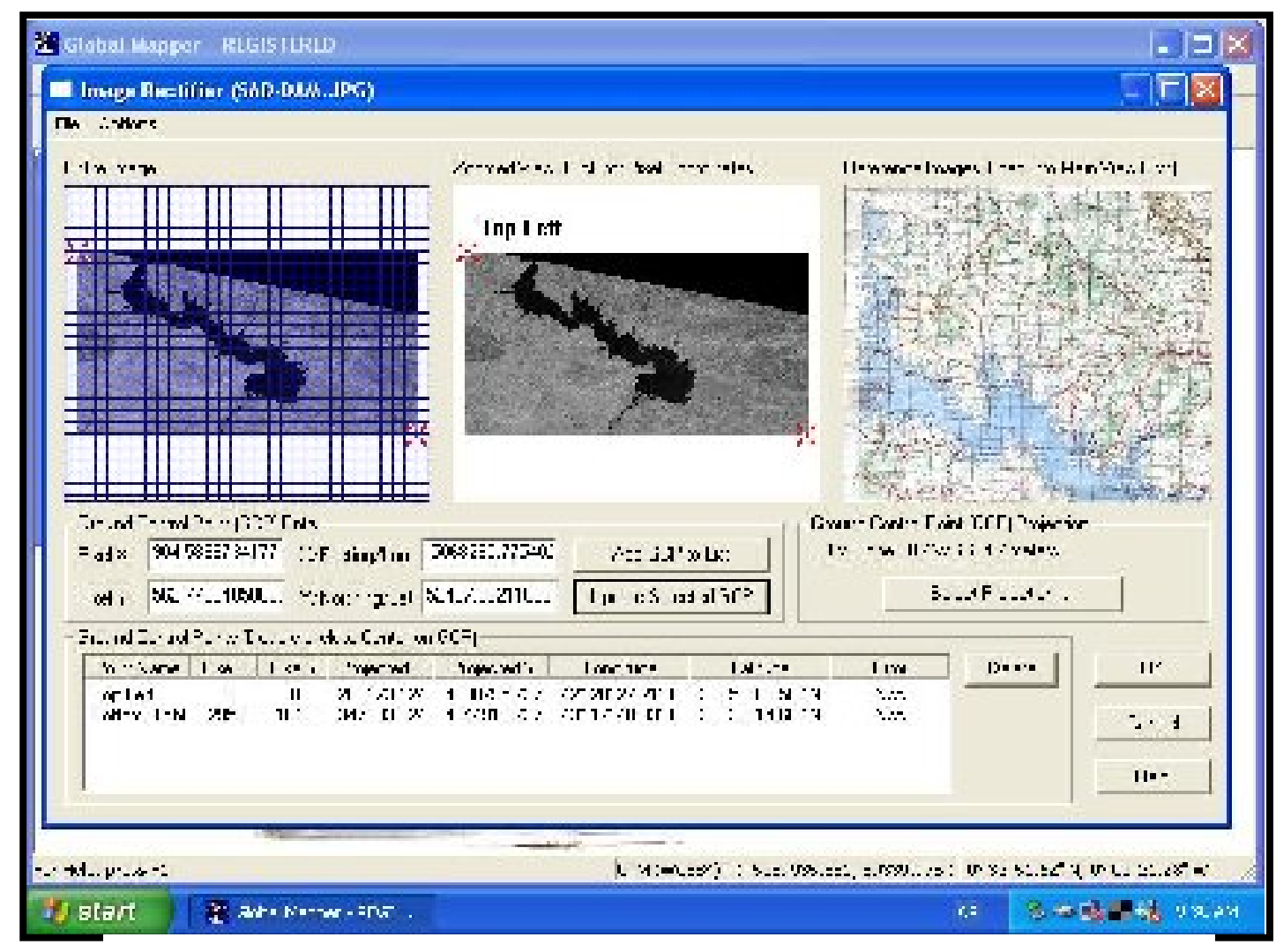

Fig. 5: The georeferencing process by GM9.2 
Through the alignment stage, we determined in advanced what points will be our control points that is, points that can be found on both TM digital image and the reference topographic map. These will act to align the image to the required spatial data. (Figure 6) shows the TM image after the georeferencing process by using GM9.2 package software. The georeferencing process was performed according to World Geodetic System1984 (WGS84) ellipsoid and projection of Universal Transverse Mercator (UTM). The UTM coordinate of the indicated red-white circle in the image was (Easting $(E)=305217.213 \mathrm{~m}$, Northing $(\mathrm{N})=4055962.409 \mathrm{~m})$. Finally, the georeferencing process is very important step to obtain the possibility of high accuracy level of the output results in the calculating process of the selected area that have been adopted in the study.

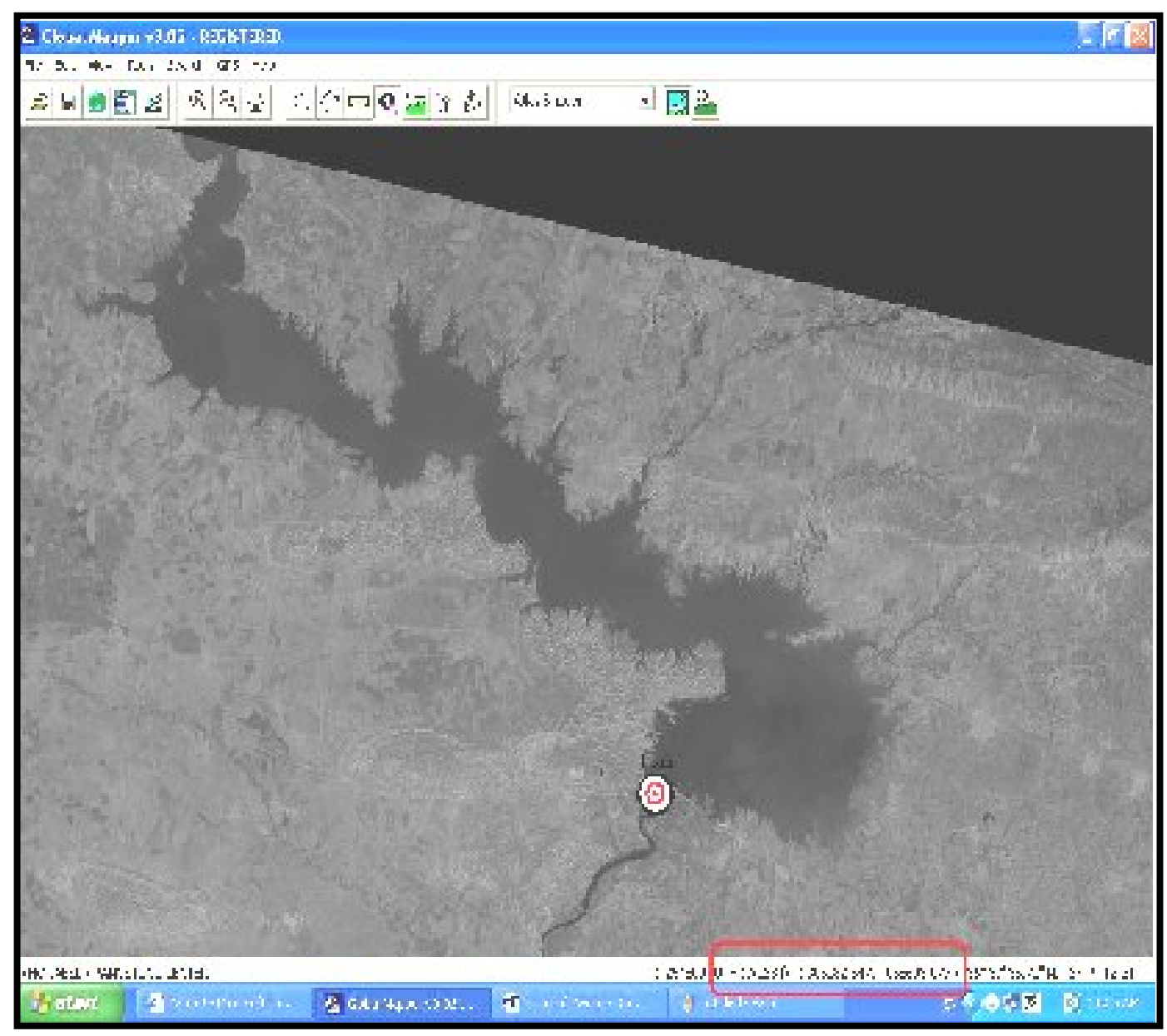

Fig. 6: Study area after georeferencing process 


\section{DIGITAL CLASSIFICATION}

Digital classification of a given dataset means the division of these data according to the degree of closeness and similarity in the satellite images (Kemenede et al., 1999). Each pixel in the image can be represented by vector pattern, therefore, each elements of these pattern defined the surface reflectivity with a different spectral bands for the operating sensors, which have been used in the acquiring of the image features. Hence, the surface reflectivity is usually called as a spectral signature. Therefore, the digital classification of the remote sensing dataset in its private means refer to the dividing of the vector patterns into classes depending on the degree of similarity or difference in the spectral signatures of the surface landcover. There are two main types of classification: supervised and unsupervised classification (Lillesand and Kiefer, 2000). The supervised classification was adopted in the current study for isolating the class, which required calculating its area. This classification type required to identify or representative sampling of the pattern of class or landform that is called training areas, which is a guide for the classification of spectral characteristics of each class. For the purpose of completing the classification process on the satellite image used in the current study, the supervised classification has been selected through the selection of several training areas on each class to complete the calculation process of the Mosul Dam Lake's area, so as to isolate this area and incorporated into one class accurately (Fig. 7). The Maximum Likelihood methods have been adopted to isolate the classes precisely according to the following equation (Profeti, 2003):

$$
\begin{aligned}
& d_{i}(x)=\ln P\left(w_{i}\right)-\frac{1}{2} \ln \left|C_{i}\right|-\frac{1}{2}\left[\left(x-\mu_{i}\right)^{\prime} C_{i}^{-1}\left(x-\mu_{i}\right)\right] \\
& i=1,2, \ldots \ldots, \mu
\end{aligned}
$$

Where: $P\left(w_{i}\right)=$ Prior probability density

$\left|C_{i}\right|=$ Determinate of matrix $C_{i}$

$C_{i}=$ Covariance matrix of class $i$, it is symmetric and positive

$x=$ input vectors

$\mu_{i}=$ mean vector

$\mu=$ pattern class

The input vector $x$ is assigned to the class that shows maximum $d_{i}(x)$.

\section{RESULT AND DISCUSSION}

For the purpose of testing the efficiency of the method used in the current study to calculate the area of a given region, Mosul Dam lake area has been chosen as a case study, because of the availability of their field data and satellite images. According to the basic stages in the current study, digital filtering process was conducted on the satellite image by the application of the high pass spatial filtering mode (Laplace) to determine the number of the pixels contained in the lake. After applying the process of geometrical registration related to the correction the pixels dimensions of the lake, the image of the lake have been classified into five classes, the region of the lake included the class apparently red. Through the used software package, the number of pixels 
existing in the lake class has reached (417221) which were covered all parts of the lake (Fig. 7). Note that the class type (red color) exists only on the lake area and not appear in any other region in the total satellite image because of the using of supervised classification through:

1. Selecting many training areas of classified lake.

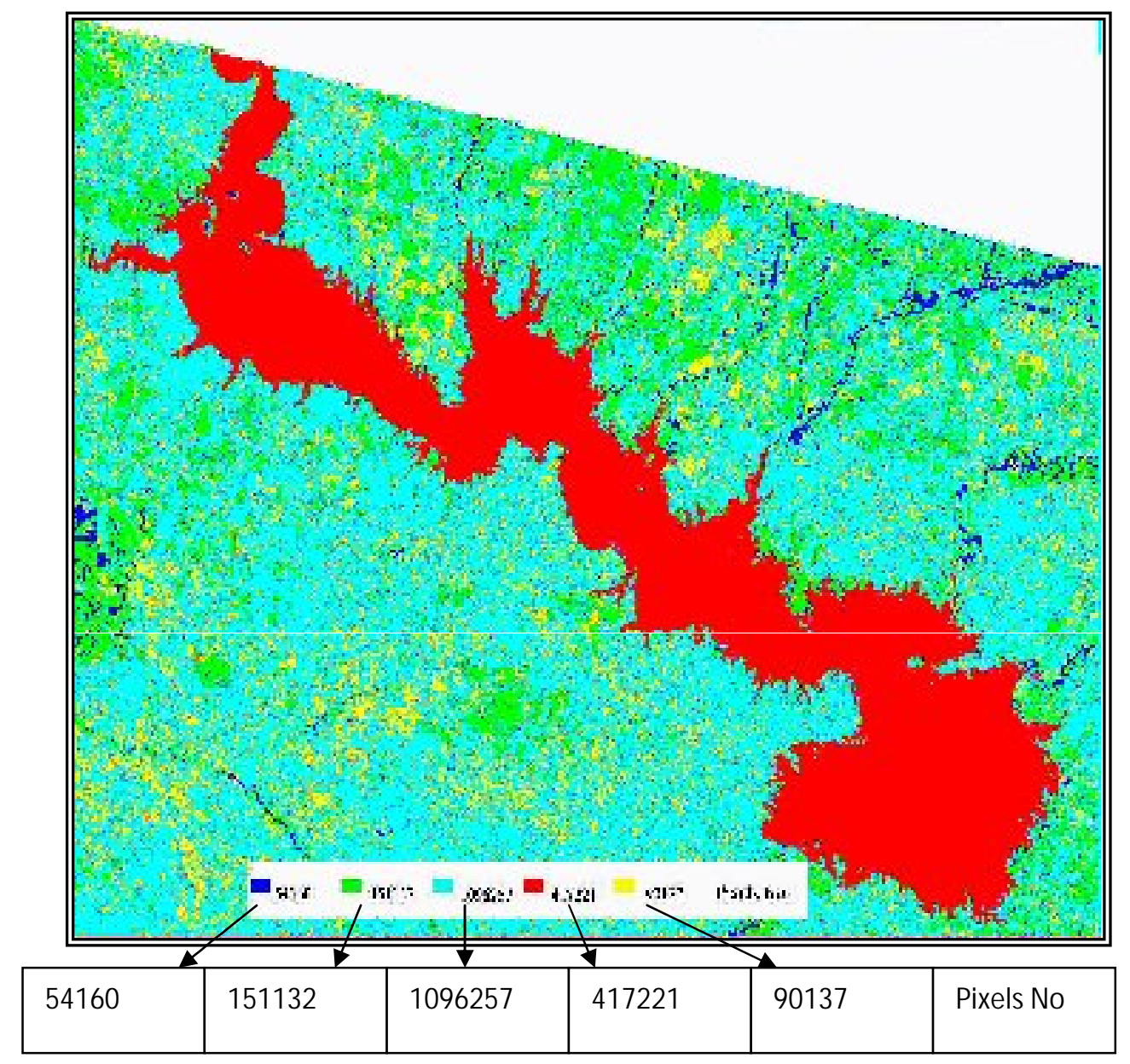

Fig. 7: Digitally classified Image

2. determining the number of appearance class in the satellite image precisely because the non-real increasing or decreasing in the number of classes leads to giving a false classes (in the case of the increase) and to the neglect of certain class and merger with others (in the case of decrease). After identification of the Lake class pixels, the area of the lake has been calculated depending on the resolution of Landsat thematic Mapper Image (TM). It is known that the spatial resolution of TM image is $(30 \mathrm{~m})$, that's mean the dimensions of the single pixel is $(30 \mathrm{~m} \times 30 \mathrm{~m})$, in other word, each pixel represents an area of $\left(900 \mathrm{~m}^{2}\right.$ or $\left.0.0009 \mathrm{Km}^{2}\right)$ on the earth surface. As previously mentioned that the Lake area class contains (417221) pixels, then the Lake area will be:

$417221 \times 0.0009=375.5 \mathrm{Km}^{2}$ 
For the comparison purpose, GIS software (GM 9.2) has been applied for calculating the Lake's area in the same image by digitizing process (Drawing a Polygon feature). As shown in (Fig. 8), the area of the Lake is $\left(357 \mathrm{Km}^{2}\right)$, while the calculated area in the present study is $\left(375.5 \mathrm{Km}^{2}\right)$. The previous results were compared with the traditional method to calculate the area from topographic maps. This method was dependent on the total number of complete squares and the total number of the missing squares that covered the class which are extracted from the topographical map of the study area by the follows equation:

Area of the class $=($ number of complete squares + number. of the missing squares $/ 2) \times \mathrm{km}^{2}$.

According to the scale of the adopted topographic map in this study (1:100000) as shown in (Fig. 5), the output result was found to be :

Area of the class $=(257+223 / 2) \times 1^{2}=369 \mathrm{~km}^{2}$

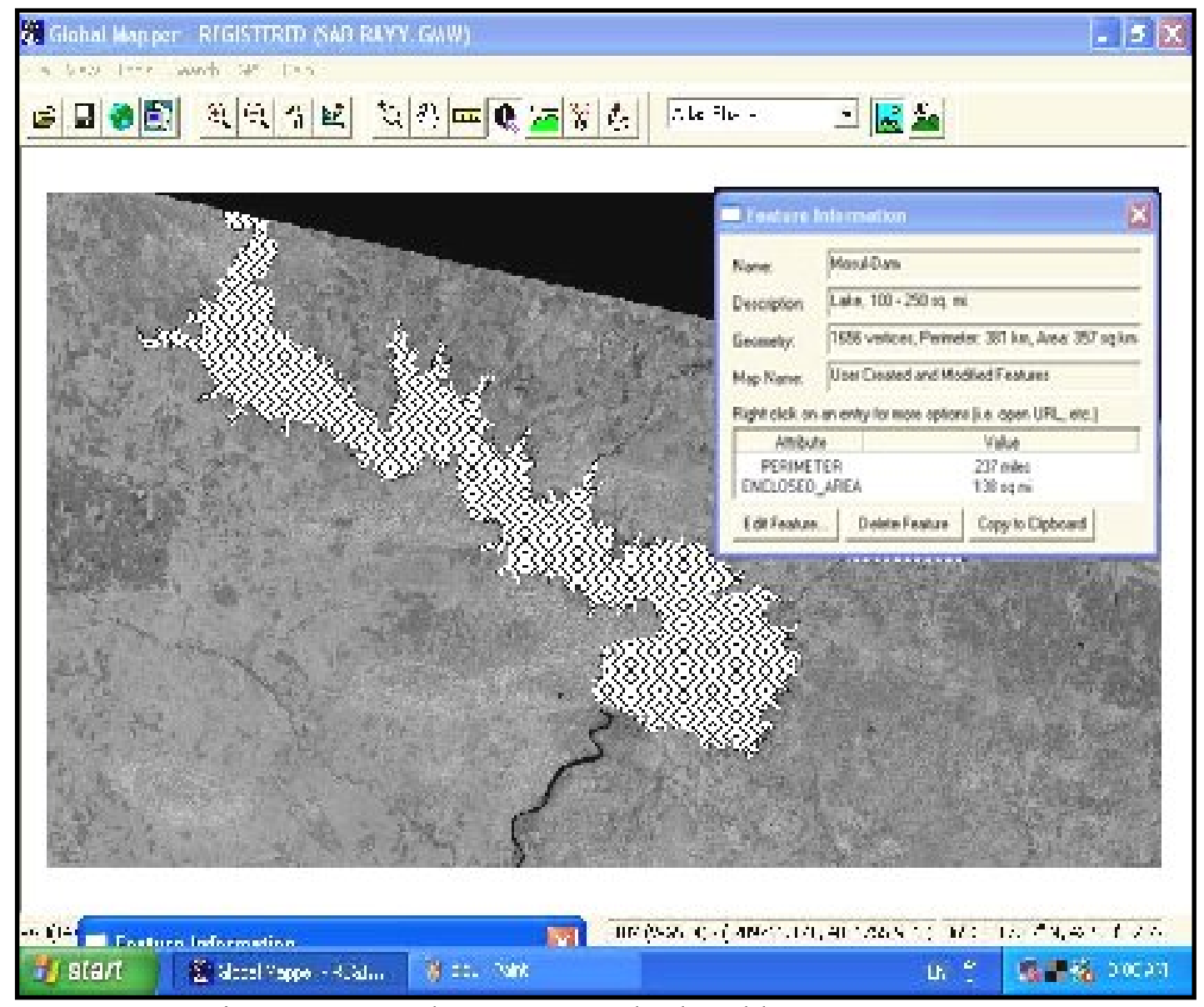

Fig. 8: Dam Lake Area as calculated by GM 9.2

This result support the aim of the present study to estimate the area of given region with a relatively acceptable level of accuracy, this is due to:

1. The proposed method calculated the area with acceptable accuracy after prior processing (Spatial filtering and geometrical registration). 
2. The use of digital supervised classification works to isolate every type of class that appeared on all parts of the image precisely because of the selecting of multi-training areas to each class. Therefore, this method will be preferred as compare to the GIS method which the calculating of the area required a drawing of polygon features that covered all the part of the class distributed in the image, and this is will lead to the probability of inaccuracies in the identification of classes or failure to identify a part of the class which affects on the accuracy value of the estimated area.

\section{CONCLUSIONS}

In the outcome of conducted research the following are concluded:

1. The integration between image processing techniques with image satellite was a very important role in the processing operations that are included; analysis and spatial classification. This importance leads to increase the performance in any study that is depending on the theory and field analysis as a basic reference dealing with programming to get the accurate result.

2. The result of the study revealed that the proposed flow diagram could be applied as approach to recent studies, which requires estimating the area regularly and continuously.

3. The applying of the current study on multi date satellite images can be given, for example, an indication of the proposed areas of locals contaminations and their development, hence there will be a speed in decision-making by officials or specialists to limit the spreading of this disaster. Therefore, the procedure adopted in the study will be effective as compare to the dealing with this phenomenon through traditional means such as the customary survey field.

\section{REFERENCES}

Al-Alaaf, A. A., 2002. An Interactive Software for Image Registration Using New Algorithms. Msc. Thesis, University of Mosul, Iraq, 93p. (In Arabic)

Al-Banaa, R. Gh., 2005. Comparison of Digital Classification Product and its Accuracy in Landcover Classification of a Part of Mosul City. Iraqi Geological Journal, Vol. 5, No. 2, Pp. 64-77. (In Arabic)

Al-Emadi A.T.; Al-Allaf. A.M. and Al-Shumam T.A., 2004. Software for Image Processing in Remote Sensing. Remote Sensing Centre, Mosul University.

Clarke, K.C., 1999, Getting Started with Geographic Information Systems, 2nd edition, Prentice-Hall, Inc., 338p.

Gozalez, R.C. and Woods, R. E., 2002. Digital Image Processing, $2^{\text {nd. }}$ Prentice- Hall, Inc, $793 \mathrm{p}$.

Jezching, T., 1989. Registering Landsat Image by Point Matching, IEEE Transaction on Geoscience and Remote Sensing. Vol. 27, No. 5, pp.642-651.

Jones, C.B., 1997. Geographical Information Systems and Computer Cartography. Addison Wesley Longman Ltd. 318p.

Kemenade C.H.; Poutre H.L. and Mokken R.J., 1999. Density-Based Unsupervised Classification for Remote Sensing,Springer-Verlay Berline, 290 p. 
Kumar, M., 2008. Digital Image Processing, Photogrammetry and Remote Sensing Division. Indian Institute of Remote Sensing, Dehra Dun, pp81-108, Available at: www.wamis.org/agm/, Accessed at: 28/ May/2008.

Lillesand, T.M. and Kiefer, R.W., 2000. Remote Sensing and Image Interpretation, 2 nd Ed. John Willey and Sons Incop., New York, 721 p.

Maling D.H., 1983. Coordinate System and Map Projection. Ebenezer Baylis and Sons Limited, London, 367p.

Mather, P.M., 1987. Computer Processing of Remotely Sensed Images, An International, John Wiley and Sons. 212p.

Profeti, G., 2003. Fundamentals of Remote Sensing Image Processing (Lecture Notes). $60 \mathrm{p}$.

Zhou, Q., 1999. Digital Image Processing and Interpretation. Department of Geography, Hong Kong, Baptist University, 45p. 